http://dx.doi.org/10.18675/1981-8106.vol26.n51.p126-141

\title{
Arquivo Pessoal: os Guardados de uma Professora Contando Histórias
}

\author{
Personal file: saved roles of a teacher telling stories
}

Archivo personal: los Recuerdos de una Profesora Contando Historias

\section{Antônia Simone Coelho Gomes'}

'Programa de Pós Graduação da Universidade do Estado do Rio de Janeiro (PROPed UERJ), Rio de Janeiro - Brasil. E-mail: antoniasimone.gomes@gmail.com

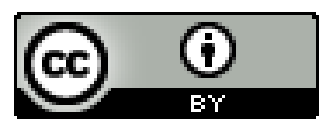

Educação: teoria e prática, Rio Claro, SP, Brasil - eISSN: 1981-8106

Está licenciada sob Licença Creative Common

\section{Resumo}

O trabalho com arquivos pessoais de professoras vem ampliando as formas de se perceber trajetórias profissionais, além de permitir uma visibilidade das práticas pedagógicas desenvolvidas no cotidiano escolar. O objetivo deste texto é entender como ao desvelar o arquivo pessoal de Djanira Vaz Pereira, professora/ex-diretora da Escola Estadual Melo Viana- dentre eles, documentos, escritas pessoais, fotografias e uma série de registros no que diz respeito à sua trajetória profissional- compreende-se as relações da escola que vão além da sala de aula e abrem-se possibilidades para que as práticas pedagógicas adotadas nas escolas públicas de Minas Gerais, em meados do século XX, sejam revisitadas. A guarda de documentos sugere mais do que uma preocupação sistemática com a preservação do passado escolar, mostra-se como um esforço em dar um sentido a esse material constitutivo do eu, que possui interlocução entre a construção da autoimagem e as cenas do cotidiano profissional. O presente estudo projeta o olhar sobre o lugar e a importância em se trabalhar com arquivo pessoal de professoras que fazem de seus guardados um legado para se entender a educação.

Palavras-Chave: Arquivo Pessoal; Escrita Autobiográfica, Arquivo de Professoras. 


\begin{abstract}
Working with personal archives of teachers has expanded the ways to realize professional careers and allows visibility of pedagogical practices developed in the daily school. The aim of this paper is to understand the school relationships that go beyond the classroom and open up possibilities for the pedagogical practices in public schools in Minas Gerais in the century XX. It was used documents, personal writings, photographs and a series of records about professional career of Djanira Vaz Pereira, a teacher-former director of the Melo Viana School. The storage of documents suggests more than a systematic concern for the preservation of the academic past, appears to make sense of this constitutive material itself, which has in the dialogue between building self-image and scenes of daily professional work. The study takes us design our eye on the place and the importance of working with personal archives of teachers that make their own records, a legacy to understand education.
\end{abstract}

Keywords: Personal Archive; Autobiographical Writing; Teachers Archive.

\title{
Resumen:
}

El trabajo con archivos personales de los profesores ha ampliado las formas de concebir una carrera profesional, además de permitir la visibilidad de las prácticas pedagógicas desarrolladas en la escuela todos los días. El objetivo de este trabajo es entender cómo revelar el expediente personal de Djanira Vaz Pereira, profesor/ex director del Melo Viana Escolar-entre ellos, documentos, escrituras personales, fotografías y una serie de registros en lo que respecta a su carrera profesional- se comprende las relaciones de la escuela que van más allá del aula de clases y se abren posibilidades de las prácticas pedagógicas en las escuelas públicas, en Minas Gerais , a mediados del siglo XX, para que se las revise. El almacenamiento de los documentos sugiere más que una preocupación sistemática por la preservación del pasado escolar, se lo ve como un esfuerzo por dar sentido a esta materia constitutiva del yo, que establece un diálogo entre la construcción de la propia imagen y las escenas de trabajo diario. El estudio lleva a diseñar nuestro ojo en el lugar y destaca la importancia del trabajo con el archivo personal de los docentes que hacen de sus recuerdos un legado para entender la educación.

Palabras clave: Archivo Personal; Escritura Autobiográfica; Archivo de Maestros. 


\section{Introdução}

O dever de arquivar as nossas vidas é onipresente na nossa sociedade. Quer seja na vida diária, no espaço social ou na esfera familiar, ou ainda no quadro de práticas comunitárias, devemos nos entregar com frequência a esta prática (ARTIÈRES,1998, p.18).

O trabalho com arquivos pessoais de professoras vem ampliando as formas de se perceber trajetórias profissionais e permite uma visibilidade das práticas pedagógicas desenvolvidas no cotidiano escolar. O objetivo deste texto é entender como ao desvelar o arquivo pessoal de Djanira Vaz Pereira, professora/ex-diretora da Escola Estadual Melo Viana- dentre eles, documentos, escritas pessoais, fotografias e uma série de registros no que diz respeito à sua trajetória profissional- compreende-se as relações da escola que vão além da sala de aula e abrem-se possibilidades para que as práticas pedagógicas adotadas nas escolas públicas de Minas Gerais, nos meados do século XX, sejam revisitadas. Toca-se numa preocupação no campo da educação que tem levado pesquisadores, a exemplo de Mignot; Santos (2003), Mignot; Souza (2008), Passegi (2008), a trabalharem com histórias de mulheres professoras que são produtoras de registros que retratam o cotidiano escolar.

Este trabalho resultou da pesquisa sobre memória escrita escolar desenvolvida no Curso de Pós Graduação em Educação da Universidade do Estado do Rio de Janeiro (UERJ), onde a memória da Escola Estadual Melo Viana- MG foi tomada como objeto de estudo e se procurou entender como uma escola pública se consagra na cidade. Ao longo da pesquisa foram realizados estudos que enfocam a cultura escolar com base em Vinão Frago (1995) e Escolano (2000), autores que consideram a escola como lugar de produção de uma cultura específica. Nessa articulação foram evidenciadas as relações que pressupõem a modernidade de um projeto arquitetônico e se impõe pela organização e ordenamento do mobiliário e dos objetos expostos no salão nobre da escola. Também teve destaque a escrita produzida por professores (as) e alunos que dão centralidade às práticas escolanovistas, além do material iconográfico que confere sentidos ao que foi vivido. Em se tratando do percurso metodológico, foram realizadas quatro entrevistas, oportunidade em que se esteve em contato com os documentos que constituem o arquivo pessoal de Djanira podendo-se então iniciar a tessitura dos fios da memória em busca dos sentidos atribuídos às experiências vividas. Essa tarefa exigiu o entrecruzamento entre a escrita autobiográfica, documentos oficiais e um tanto de papéis amarelados que no seu conjunto foram tomados como fonte de investigação.

Os arquivos pessoais guardam em si uma dimensão de preservação da memória por resguardarem nos escritos e nas fotografias o valor informativo cuja intenção é a utilização dos dados para fins históricos. Sobretudo, asseguram o valor social que evidencia não só o que foi produzido pelo titular, mas também acumula os discursos produzidos por terceiros. Trabalhar 
com arquivo-memória envolve uma dimensão simbólica de natureza afetiva entre presente e passado, de modo a estabelecer um diálogo entre aquele que guarda os papéis e aquele que está investigando. Nas palavras de Ribeiro, “o que os arquivos pessoais podem atestar, o que o desejo de guardar os próprios documentos pode indicar, será esse anseio de ser, a posteriori, reconhecido por uma identidade digna de nota" (1998, p.35). Ao remexer baús e caixas que guardam as lembranças escritas, fotografias e objetos, o sujeito mergulha para dentro de si e faz-se escafandrista de sua própria identidade, num movimento de recuperação de sentidos, no qual procura entender melhor quem é. Nesse movimento configura-se a oportunidade de fazer um balanço geral da vida, prestando conta do que fez e como fez.

$\mathrm{O}$ arquivo memória de Djanira se constitui por um conjunto de documentos que dá visibilidade ao percurso do vivido, eterniza sua experiência como professora e revela suas ações no campo administrativo, maneira pela qual foi conquistando, gradualmente, respeito e consolidando o papel de protagonista na educação carangolense. Este pode ser dividido em 2 conjuntos de registros. Um reúne os documentos de natureza escolar dos quais fazem parte um caderno de plano de aulas, mensagens enviadas às professoras, telegramas, cartões recebidos de políticos, cartões de felicitações pela passagem de aniversário, bilhetes de alunos, convite da $1^{\mathrm{a}}$ turma do pré-escolar da Escola Melo Viana, da qual foi paraninfa, e os documentos relacionados à Secretaria de Educação. Mensagens de agradecimento enviadas pela Escola Estadual Emília Esteves Marques, por ocasião da enchente de 1985, quando o prédio da Melo Viana foi cedido para abrigar os alunos da referida escola, assim como cartinhas dos alunos enviadas à diretora em agradecimento à acolhida. Dentre seus guardados também sobressaem uma dezena de certificados, homenagens e placas que são testemunhos da profissional que tem sua atuação reconhecida no espaço público e reúne nesses registros a importância da educadora em Carangola. Na sequência, aparecem os convites da formatura do curso ginasial e do curso normal, diplomas e certificados de cursos de aperfeiçoamento, documentos que estão intrinsecamente ligados à trajetória profissional e consolidam o processo de formação docente.

A segunda fonte se refere à escrita de natureza autobiográfica. São manuscritos em que a autora rememora o início da carreira no Grupo Escolar na cidade de Fervedouro e retrata o tempo memorável em que permaneceu à frente da direção da Escola Estadual Melo Viana, em Carangola. Nesse conjunto encontram-se poesias e poemas de sua autoria, letras de músicas, cartas, recortes e publicações em jornais que registram suas conquistas como figura pública. Desvendar o arquivo-memória revela a intenção de escrever sobre si, guardar objetos e papéis escritos, instala a prática de arquivamento do eu, desenvolve uma rede de significações que dão lugar a um movimento de subjetivação, revela uma intenção autobiográfica.

O presente texto foi organizado para que a reflexão incidisse sobre como o arquivo pessoal, enquanto produção social e espaço voltado para a guarda dos registros do vivido cumprisse o papel de produzir sentidos sobre o processo de subjetivação. A primeira parte permite compreender o percurso do processo pessoal e profissional e ilustra as concepções de 
educação em Minas Gerais nas décadas iniciais do século XX. Na segunda parte, a intenção foi dar visibilidade ao conjunto das 15 mensagens destinadas às professoras por ocasião das reuniões pedagógicas realizadas por Djanira no período em que permaneceu na direção da escola Melo Viana. As mensagens foram analisadas com base no "caminho narrativo" (GALVÃO, 2000), procedimento que tornou possível identificar os princípios básicos que serviram como estratégia administrativa para o desempenho profissional e representação do que é ser uma "boa professora".

\section{Arquivo-memória: papéis e fotografias que contam histórias de vida}

Djanira Vaz Pereira Netto nasceu na cidade de Carangola ${ }^{1}$ no dia 13 de maio de 1929, filha de Marcelino Vaz e Edith Vaz Netto, a mãe morreu muito cedo, ficando sua educação desde os treze anos por conta do pai. Essa mulher-professora traz algo peculiar com o lugar em que nasceu, viveu toda a sua vida ali, estudou e trabalhou no mesmo espaço: Minas Gerais. No tempo em que era menina, as solicitações do ambiente eram poucas, a televisão ainda não existia, o cinema não havia chegado a Carangola, as informações eram lentas e demoradas, a comunicação entre os lugares era restrita. Os documentos e as fotografias, referentes ao período de 1959 a 2002 que estão reservados em uma grande caixa e organizados em pastas, constituem-se como o seu arquivo-memória. Passo a passo, a vida pessoal e profissional dessa mulher/profissional da educação foi sendo revelada, não por uma perspectiva oficial, mas pela ótica de quem recupera os fragmentos da própria vida em papéis amarelados pelo tempo.

Assim como muitas professoras que escrevem suas lembranças recorrendo ao tempo de quando foram alunas, Djanira evocou com carinho suas professoras das primeiras letras, reavivando as relações desenvolvidas no lugar onde vivenciou parte de sua vida, as quais estão relacionadas com as representações do espaço-escola. Os manuscritos de 2001, intitulados "Minhas Lembranças Queridas", revelam vivências da escola da infância e servem como detonadores de lembranças significativas: "D. Ester Morando foi minha primeira professora, ela ensinava de forma acolhedora, mas imprimia um ensino que reunia atenção, firmeza e afeto. $\mathrm{O}$ funcionário Sr Aristides era o zelador da escola e D. Zulmira quem vendia o pé de moleque, pão com salame e cocada: tudo tão delicioso!" Os amigos do tempo dos bancos escolares também tiveram seus nomes registrados: "Georgeta, Hizi, Euda, Walker, Dirim, Sidney", aqui representam os laços de amizades que se formaram na infância e que se mantiveram ao longo dos anos.

\footnotetext{
${ }^{1}$ Carangola, cidade que está situada a leste do estado de Minas Gerais, pertencendo a Zona da Mata. População em 2014 de 33412 habitantes. Na economia destacam-se o café, o leite, a pecuária, a indústria de laticínios. 
Os fragmentos de escrita autobiográfica nos transportam no tempo e discorrem sobre as práticas pedagógicas adotadas nas escolas mineiras do século XX: “[...] as aulas de canto que aconteciam no Grupo Escolar Melo Viana ${ }^{2}$ eram ministradas pela professora Orita Pinheiro e eu estava sempre presente nos auditórios da escola, declamando, dramatizando, cantando." Outras experiências cotidianas sobressaem na escrita de natureza autobiográfica, junto às suas vivências emergem indícios das práticas institucionalizadas pelas escolas mineiras: "naquele tempo o recreio dos meninos era separado do recreio das meninas. O pátio era dividido por um muro alto para estabelecer essa separação.”, “[...] tínhamos ginástica com a professora Celina e fazíamos exercícios com bolas de madeira nas mãos."

As anotações deixam transparecer situações aparentemente comuns de sua vida, mas que estão carregadas de emoção, o que as tornam marcantes e cheias de significação.

Quando eu estava cursando o quarto ano com a saudosa professora D. Marina de Souza Imbeloni, ela gostava muito da minha letra e da colega Georgeta Chedid, então nos levava para sua casa, onde escrevíamos nos álbuns, desenhava e coloríamos sobre as datas comemorativas. Guardo recordações maravilhosas de nossa escola e de minhas professoras, pois marcou muito minha vida estudantil. D. Marina era uma pessoa que gostava de elogiar nossos trabalhos. Quando escrevíamos, ela falava: que letra bonita! Que capricho! Tão redondinha! Como vocês conseguem escrever tanta coisa bonita neste espaço tão pequeno? Eu e Georgeta ficávamos orgulhosas e felizes ("Minhas lembranças queridas", 2001. Fonte: Arquivo pessoal da prof. Djanira).

As lembranças do tempo da escola traduzem vivências pessoais e sociais e favorecem os conhecimentos acerca das metodologias da época. Esses elementos apontam para as formas de atuação docente e confirmam a presença de estratégias de disciplinarização aqui representadas pelas exigências de uma caligrafia perfeita, pelo capricho na letra e controle dos impulsos, habilidades necessárias para a execução de um bonito desenho.

Como observa Castillo, ao registrar as lembranças, organizar as memórias e passar para o papel parte de sua vida "o escritor rompe mordaças, quebra o silêncio e recupera o valor balsâmico da palavra escrita" (2000, p.7). São histórias que se multiplicam em tantas outras histórias, entrecruzando caminhos da identidade pessoal e profissional. O objeto da escrita autobiográfica, aqui expressa, se assenta sobre as experiências vividas e por si interpretadas, por isso pode-se dizer que se trata de um trabalho que expressa uma ideia autorreferencial. Philippe Lejeune (1975) define escrita autobiográfica como a "narrativa retrospectiva em prosa que uma pessoa real faz da sua própria existência, acentuando sua vida individual, particularmente a

\footnotetext{
${ }^{2}$ O Grupo Escolar Melo Viana foi criado em 1925. Mais informações recorrer a GOMES, Antonia. TEMPLO DO SABER: a consagração da Escola Estadual Melo Viana em Carangola - MG Dissertação de Mestrado, PROPEd, UERJ, 2002.
} 
história de sua personalidade". Daí admitir que o arquivo pessoal é, de certa forma, um projeto autobiográfico, porque "construindo seu arquivo, constrói sua expressão individual, sua imagem, seu eu, efetuando o pacto com o leitor" (FRAIZ, 1998, p.75).

$\mathrm{Na}$ segunda etapa da vida de Djanira aparecem histórias que se entrelaçam a fatos, a pessoas, a lugares e junto às suas vivências sobressaem elementos referentes ao contexto social e histórico, deixando pistas sobre a cidade. As lembranças do Colégio Carangolense, estabelecimento de ensino tido como o mais conceituado da época, constitui-se como um marco em seu percurso educacional. Nessa instituição de ensino foi campeã de vôlei e salto em altura e em 1947 concluiu o Curso Científico e o Curso Normal.

Fiz 2 anos de Curso Científico no Colégio Carangolense, 1945, de acordo com a lei vigente naquele ano, dava direito ao aluno de fazer o Curso Normal Magistério hoje - em 1 ano, em horário diferente, obedecendo a carga horária exigida. Estudava psicologia, filosofia. A prática era muito pouco, íamos assistir como uma professora experiente dava aula para seus alunos numa escola particular, esse era o estágio, a prática ("Minhas lembranças queridas", 2001. Fonte: Arquivo pessoal da prof. Djanira).

Djanira fez o curso superior bem mais tarde. A entrada na faculdade de Filosofia e Letras de Carangola representou a evolução de seus conhecimentos. Nos escritos intitulados "Recordações da sala de aula", aparecem explicitadas as expectativas em relação à alfabetização dos alunos, os projetos pedagógicos realizados e os episódios relativos à disciplina da turma. São histórias do passado que se misturam à época em que começou a carreira do magistério na pequena localidade de Fervedouro e evidenciam os dilemas enfrentados no início de carreira.

Peguei uma turma de $1^{\text {a }}$ série, com 30 alunos. Dediquei-me de corpo e alma. Fiz o magistério em 1 ano e não foi o suficiente para me orientar na sala de aula. Recorri ao programa adotado nos Grupos Escolares de Carangola. Ia até o Melo Viana para ver o programa que estava sendo adotado pelas professoras e saber quais os livros usavam. Procurava meios de desenvolver bem o meu trabalho, pois queria que eles acompanhassem o que era dado nos grupos da cidade. A professora Zezé Bretas dava aula particular, fui ter com ela algumas orientações ("Recordações da sala de aula", 2001. Fonte: Arquivo pessoal da prof. Djanira).

Os documentos reunidos no arquivo pessoal imprimem uma rede de significações e permite a recriação de sentidos das próprias ações. Eles resultam, como observa Santos (2008, p.81) tanto da "necessidade de testemunhar o vivido como de imposições e normas institucionais". Trata-se, portanto de desvendar parte da história da educação carangolense a partir dos escritos autobiográficos e dos guardados referentes à trajetória pessoal/profissional de uma professora. 
Olhar o arquivo pessoal de Djanira, nos remete às reflexões de Inês Barbosa Oliveira (2008) que considera as narrativas autobiográficas como recursos para se compreender como se consolidam as redes de saberes, fazeres e valores que acompanham os professores em seu percurso profissional. Por meio da "escrita autobiográfica se torna possível recuperar a percepção que os diferentes sujeitos da escola possuem de si mesmo, de suas trajetórias, de seus objetivos e de suas leituras de mundo" (p.163). Consideramos que as narrativas compreendidas como expressão da memória, imprimem identidade, alteridade e abrem possibilidades do sujeito ter consciência de si, propiciando o sentimento de identidade e a compreensão da subjetividade.

Holly (1992) faz uma análise de mais de 40 diários escritos por educadores e aponta para a relutância dos professores em questionar a rotina da sala de aula. Ela nos mostra que esses professores, ao se depararem com os dilemas do processo de ensino e muitas vezes com os problemas de aprendizagem de crianças, começam a encontrar inconsistências e contradições na prática, isso faz com que deflagrem conflitos e tensões entre seus pensamentos e sentimentos, fazendo com que tentem, primeiramente, alterar suas técnicas e métodos de ensino. Já no ponto de vista de Cavaco, "as redes informais, de trocas de experiências e partilha de conhecimentos, constituem principalmente sistemas consolidados de rotinas" (1995, p.167), cujos efeitos residem de certa forma em insegurança e nas ansiedades enfrentadas no cotidiano.

O "Caderno de Planejamento de Aulas" referente ao ano de 1959 e o "Caderno de Problemas Matemáticos" produzido no ano de 1961 estão dentre os documentos que compõem os guardado da professora Djanira. A "Cartilha da Ambrozina", as fichas individuais para fixação de palavras e o plano de aula que demonstra como utilizar o material concreto para trabalhar a aritmética se destacam por dentre os seus guardados de natureza escolar. Um olhar sobre esses documentos permitiu o reconhecimento de práticas pedagógicas desenvolvidas naquela época.

\footnotetext{
Para trabalhar as frações eu levava frutas, maçã, laranja, mamão, banana, para ensinar o inteiro, a metade e um quarto. Após a explicação, as fatias cortadas eu distribuía aos alunos na hora da merenda. Para o litro, eu levava a garrafa com o leite, com água, refresco e fazia o mesmo. As crianças gostavam da explicação e mais ainda do leite. Neste dia os olhinhos deles até brilhavam! ("Caderno de plano de aula", Fonte: Arquivo pessoal da prof. Djanira).
}

Tomar conhecimento das experiências das professoras por meio dos registros contidos no arquivo memória permite pensar as diferentes estratégias utilizadas para encarar os desafios da sala de aula. Pode se pensar então, que o arquivo memória da professora se apresenta não só com a função de acumular registros que ganha estatuto de relíquia por seu valor afetivo, sobretudo retrata um conjunto de práticas docentes que coloca em perspectiva a produção de uma cultura escolar. 
Revisitando o "Caderno de Plano de Aulas", foram encontradas dezenas de poemas e poesias selecionados para a programação do "Clube de Leitura" da primeira turma da 4 a série do Grupo Escolar Joaquim Bartholomeu Pedrosa, localizado em Fervedouro. Essa prática pedagógica era privilegiada dentre as atividades culturais da época. Os alunos declamavam Olavo Bilac, Cecília Meireles, Casimiro de Abreu e outros poetas. Os registros evidenciam o investimento pedagógico feito nessa atividade e contribui para o entendimento do movimento de escolarização em Minas Gerais.

Foi criado o "Clube da Leitura" na $4^{\text {a }}$ série, intitulado "Olavo Bilac", explorávamos o teatro, poesias e literatura infantil. As crianças adoravam participar das pecinhas que eu organizava e eles representavam com muita responsabilidade [...] era um trabalho de muito valor para sociabilizar o aluno e incentivar o gosto literário ("Recordações da sala de aula", 2001. Fonte: Arquivo pessoal da prof. Djanira).

A escrita de si evidencia os enredamentos cotidianos da vida profissional e exige uma introspecção que demanda as interpretações das lembranças sobre o fazer docente. Em sua escrita autobiográfica aparecem também elementos indicativos das representações do que é ser uma boa professora: "a professora precisa ter pulso forte, saber dominar a turma, ser severa na hora necessária, mas carinhosa". As narrativas revelam o que Djanira pensava sobre o ofício do magistério: "ser professora naquela época era muito bonito, era muito valorizada, apesar de o salário não ser lá grandes coisas, ser normalista era muito bem visto”.

Outras referências de natureza autobiográfica traduzem o lugar de personalidade pública que foi se consolidando ao longo dos anos que esteve na gestão da Escola Estadual Melo Viana, cargo assumido em 1968, iniciando assim uma nova etapa em sua vida. A relação de seu nome à direção da escola veio associada à ideia de modernidade. Ao chegar à nova instituição, trouxe uma responsabilidade que sobre a escola incidia: "fazer o Grupo voltar a ser como antes". Esse momento foi marcante não só em sua carreira, mas também o foi para a escola, pois a presença de uma mulher dinâmica, protótipo de uma diretora aberta a mudanças, simbolizou um caminho para a ascensão da instituição que estava passando por uma série de problemas internos que acarretava trocas sucessivas de diretoras.

No arquivo-memória, os documentos de natureza pública falam de sua trajetória, são cartões, recortes de jornais, placas de "honra ao mérito", testemunhos de um tempo em que foi diretora e desempenhou o papel resgatando a ordem e o prestígio que projetaram a escola na vida educacional e social da cidade. A chegada à Escola Melo Viana mereceu registro em seus escritos autobiográficos: "Graças a Deus eu cheguei em 1968 no dia 24 de janeiro meio cabreira... Não sabia o que iria acontecer. Nunca tinha sido diretora, ainda mais uma escola tão grande, na cidade, mas não tinha medo não! Acho que eu sempre tive muita fé em Deus...E consegui vencer." 
Aos desafios colocados pela nova função, respondeu com esforço e muita fé em Deus, pilares que lhe davam segurança. O cartão enviado pelo ex-deputado João Bello de Oliveira Filho, prefeito de Carangola no período de 03/02/1951 a 05/02/1955, foi guardado como marca de distinção:

Prezada Djanira o meu abraço

Junto mando correspondência do palácio sobre o seu difícil caso, mais uma vez peço desculpas pela demora e isso embora todo nosso empenho. Estou certo que você irá fazer voltar a ordem, disciplina e amor ao nosso tradicional grupo, pois qualidades não lhe faltam para isto. O nosso desejo é apenas este, pois temos dedicado toda atenção a este estabelecimento de ensino você terá ampla liberdade para escolher e modificar o quadro para que assim tudo dê certo, temos inteira confiança em sua ação, pois sempre foi criteriosa, responsável e excelente amiga [...] felicidades.

João Bello de Oliveira 26/6/68

(Fonte: Arquivo pessoal da prof. Djanira).

Na tessitura do arquivamento pessoal, a construção da subjetividade de Djanira Vaz emerge dentre os fragmentos autobiográficos. A diretora atribui especial ênfase a uma administração que implementou reformas com objetivo de articular elementos de mudanças, o que pode ser observado pelo fragmento a seguir:

As nossas professoras em Fervedouro (1958) já faziam provas mimeografadas e quando eu cheguei no Melo Viana tinha um mimeógrafo quebrado, não funcionava, máquina de escrever não existia. As provas eram feitas à mão com carvão comum, por incrível que pareça, pelas professoras da secretaria, eu fiquei pasma com aquilo, uma escola grande, tradicional. Eu introduzi o primeiro mimeógrafo e a primeira máquina de escrever [...]. Em 1968, adquirimos o primeiro fogão a gás, que até então era fogão de lenha e por sinal de vez em quando estava entupido. Tudo doado, a gente pedia muito também. Adquirimos três bebedouros, em 1969. Nós fizemos a iluminação do pátio, aquele pátio maravilhoso! ("Minhas lembranças queridas", 2001. Fonte: Arquivo pessoal da prof. Djanira).

Os documentos do arquivo-memória de Djanira Vaz Pereira nos fazem constatar que práticas desenvolvidas nas décadas de sessenta e setenta do século XX em escolas do interior de Minas Gerais, podem ser entendidas como estratégias da escola pública para manter o lugar do ensino de qualidade. De igual maneira, como gestora demonstra que era uma figura investida de grande competência para empreender suas realizações. 
Quanto ao conjunto de fotografias encontradas no arquivo pessoal assumem uma dimensão autobiográfica na medida em que são suportes de memória que traduzem em imagens os eventos e práticas pedagógicas desenvolvidas sob a forma de festas escolares, dos desfiles cívicos, nas competições olímpicas, ocasiões em que, especialmente, a Escola Melo Viana se projetavam na cena pública. São registros imagéticos do vivido que contam histórias das práticas que se expandiram para além dos muros escolares. As fotografias guardadas pela professora são altamente reveladoras, contam sobre os contextos em que ocorreram os fatos e servem ao propósito de vencer o tempo, tornando-a guardiã da memória escolar.

$\mathrm{Na}$ caixa em que estão reunidas as fotos, são muitas as que se referem aos festivais de danças folclóricas, ficando constatada a tentativa de demonstrar como esses eventos tornaram-se ocasiões especiais para a projeção da escola na cidade. Desvendá-las em seu conjunto é projetar luz em alguns acontecimentos, embora trabalhar com arquivo pessoal requeira entender que alguns fatos estarão em foco enquanto outros serão silenciados. As fotografias referentes aos festivais de danças folclóricas demonstram como esses eventos tornaram-se ocasiões de encontros e de socialização.

O primeiro festival de dança foi em minha gestão. Acho que eu fiz até o oitavo mais ou menos. Em 1969 foi feita a inauguração do pátio para realização das festas que eram realizadas à noite. Colocamos luz fosforescente com postes para a realização do festival de danças folclóricas. Nós começamos com os desfiles das danças folclóricas representando os estados do Brasil, e para diversificar e variar, nós passamos para as danças internacionais. Já fizemos danças argentina, húngara, portuguesa, espanhola, italiana, tudo que você pensar. Nós levávamos dois meses ou três para realizarmos uma festa... [...] eram todas maravilhosas ("Manuscritos de 2001". Fonte: Arquivo pessoal da prof. Djanira).

A reflexão sobre a natureza da fotografia, como nos alerta Ciavatta enfatiza o projeto de "construção histórica destinada à perpetuação de alguma memória" (2002, p.40). Como se pode constatar, as fotos agem como pano de fundo no cenário político na busca de "monumentalizar" um período que coloca em destaque a imagem pública da diretora: "aqui eu com o Governador de Minas Gerais Francelino, aqui outra fotografia com Magalhães Pinto, por ocasião da inauguração da Exposição Agropecuária ${ }^{3}$. Percebe-se, assim, o empenho e a dedicação para edificar o trabalho ao qual ela se refere com tanto orgulho.

Sem dúvida, o que vemos é que nos registros que compõe o arquivo pessoal/profissional dessa professora/diretora, há documentos que adquirem o status de documento-memória na

\footnotetext{
${ }^{3}$ A exposição agropecuária é uma festa local que mostra a cara da cidade e oportuniza a exibição de produtos agrícolas, a pecuária, a indústria e o artesanato da região, além de reunir centenas de pessoas que retornam à cidade natal.
}

Educação: Teoria e Prática/ Rio Claro/ Vol. 26, n.51/ p. 126-141/ Jan-Abr. 2016. 
medida em que dão visibilidade a importantes fatos relacionados à História da Educação de Carangola.

\section{As mensagens dirigidas às professoras como práticas sociais}

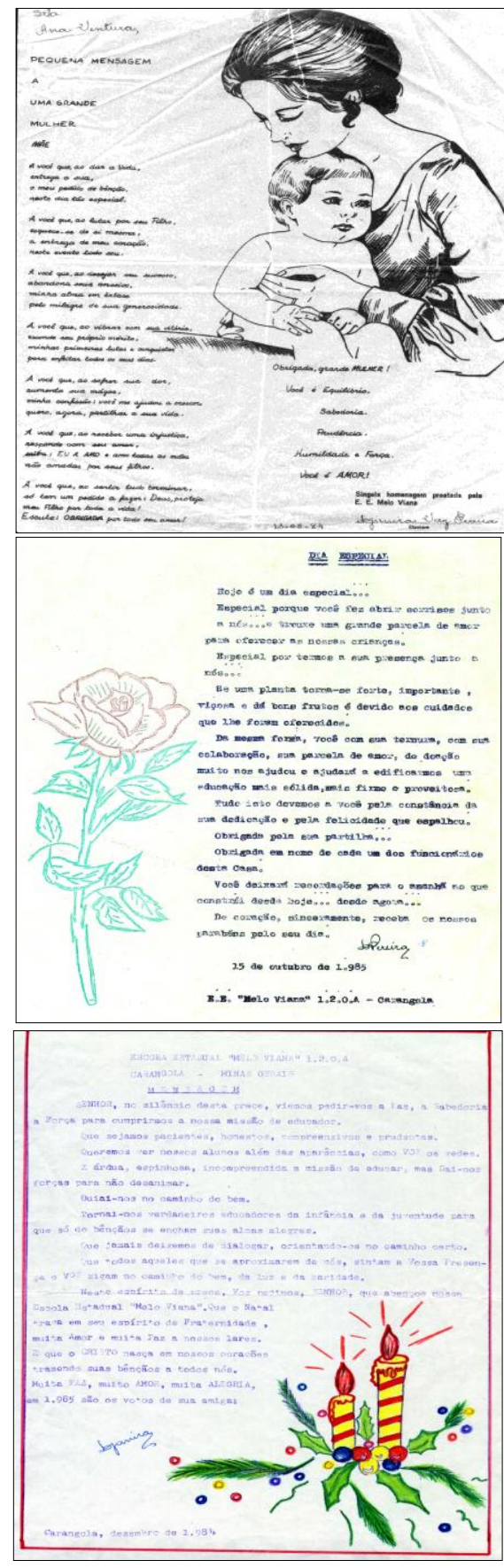

Mensagens enviadas às professoras - Fonte: Arquivo pessoal da prof. Djanira, 2001.
Para entender um pouco mais sobre o sentido do arquivo memória como prática de arquivamento, foi realizada uma imersão sobre o conjunto constituído por 15 mensagens dedicadas às professoras por ocasião das reuniões pedagógicas ou em datas comemorativas. Estas se apresentam como práticas relacionais de caráter administrativo com forte apelo afetivo cuja intenção era interferir no desempenho escolar e instalar uma afetividade nas relações entre a direção e o corpo docente. São mensagens escritas em folhas de papel ofício ou papel jornal, batidas à máquina com letra de tamanho adequado para uma boa leitura, sempre mimeografadas. $\mathrm{O}$ texto escrito, geralmente ocupava a parte central da folha, sendo reservado um espaço para uma figura de mãe, de Nossa Senhora, de flores ou de motivos natalinos. No conjunto das mensagens alguns temas sobressaíram: o dia do Professor, o Natal, o Dia das Mães e formas para desenvolver um ensino de qualidade. Aparecem as representações femininas sobre o que é ser professora e sobre o chamado ao novo das práticas pedagógicas. Nesse material escrito encontram-se as representações que essas mulheresprofessoras deveriam construir sobre si mesmas sinalizando para o que se esperava delas nas relações do ambiente escolar.

Para proceder à compreensão dos possíveis sentidos contidos nas mensagens, adotei a análise dos textos com base no "caminho narrativo" (GALVÃO, 2000), o que significou iniciar a observação por meio de leituras flutuantes, recurso que me possibilitou a percepção das especificidades do discurso. Tomando por principio essa metodologia pude definir algumas categorias que foram escolhidas por sua repetição ou frequência, como também pela importância enfatizada na escrita. Foi possível verificar que os temas propostos giravam em torno de três eixos principais: os modelos de condutas exemplares, os aspectos morais e religiosos, os padrões de comportamento relacionados ao gênero feminino. O que nos leva a inferir que, sem dúvidas, ser professora do Grupo Escolar Melo Viana representava assumir não só o lugar de transmissora do saber como ser figura referência dos princípios morais e dos bons costumes. A mensagem a seguir é ilustrativa deste aspecto: 
Senhor,

no silêncio desta prece, vimos pedir-vos a paz, a sabedoria, a força para cumprirmos a nossa missão de educador. Que sejamos pacientes, honestos, compreensivos e prudentes. Queremos ver nossos alunos além das aparências, como vós os vedes [...]. Tornai-nos verdadeiros educadores da infância e da juventude para que só de bênçãos se encham suas almas alegres. Que jamais deixemos de dialogar, orientando-os no caminho certo [...]. (Fonte: Arquivo pessoal da prof. Djanira).

O sentido contido no conteúdo dessa mensagem incide sobre os valores que toda professora deve reunir para o exercício de sua função de educadora. A produção discursiva aqui representada configura-se igualmente como uma estratégia de convencimento e persuasão que serve para comunicar a ordem escolar de forma subliminar. Nesse sentido, as mensagens foram tomadas como dispositivo o que Foucault (1986, p. 244) denomina como um conjunto de práticas que se constituem em uma trama de saberes atravessados por forças imanentes que constroem a subjetivação do sujeito. Esse entendimento pressupõe que as mensagens enquanto dispositivo de poder operam como um instrumento estratégico de empreendimento na proposta educacional cuja finalidade era sensibilizar e mobilizar quem as recebia. Estas funcionavam como molas propulsoras de motivação e convencimento, recurso estratégico que servia para estimular, desenvolver a autoestima e valorizar o investimento nas potencialidades de cada professora. As mensagens enquanto projeto de construção de identidade docente carregavam uma grande carga religiosa de cunho catequizador, expressões que se associam ao exercício do magistério como uma missão. A presença da vertente religiosa ainda que assegurada pelo uso de uma linguagem lírica pode ser observada a seguir:

Senhor

Tu és o Deus de toda beleza e de toda grandeza

Teu nome é grande e o universo inteiro é pouco para contar a tua magnificência

Tu me deste a missão de ensinar [...]

Tenho a missão de mostrar-lhes o caminho da cultura, da verdade e da ciência.

Eu te agradeço as luzes que sempre me dás e me continuas a dar. Eu levo meu espírito até a tua presença, Deus de toda a sabedoria, para pedir-te o mais precioso de todos os dons que é justamente a sabedoria de poder mostrar tua pessoa a todos àqueles que passam por minhas mãos.

Amém. (Fonte: Arquivo pessoal da prof. Djanira). 
Observa-se como essa escrita se encarregava de impregnar o outro com as palavras. No fluxo das relações institucionais, essas mensagens também transmitiam saberes, estabeleciam regras, supunham uma aquisição progressiva das competências, a qual permitia uma certificação dos conhecimentos adquiridos.

Como visto até aqui, o arquivo pessoal dessa professora é constituído por critérios na seleção e organização dos documentos que anunciam não só a intenção de preservar histórias, como também carrega a intenção de dar visibilidade ao trabalho por ela desenvolvido. $\mathrm{O}$ enfoque que é dado ao documento anuncia pontos de vista e maneiras de interpretar o vivido nas práticas escolares cotidianas. É evidente que muitos detalhes são silenciados, mas é também um dos aspectos intrínsecos dessa prática que revela a subjetividade de quem os guardou.

\section{Para terminar....}

Ainda dentre as relíquias do arquivo pessoal de Djanira Vaz encontramos um envelope com mensagens de agradecimento enviadas pelos alunos da Escola Estadual Emília Esteves Marques por ocasião da enchente de 1985, quando o prédio do Melo Viana acolheu os alunos e professores da referida escola.

Agradecer é nosso dever

Agradecer, sim tudo aquilo que a senhora fez por nós. D. Djanira, a senhora é e sempre será lembrada por todos nós, pela sua compreensão, dedicação e carinho por ter nos acolhido no colégio do qual a senhora luta para o bem estar de todos nós, hoje, amanhã e depois... Por isso nós a temos como a segunda mãe, mãe da gentileza do amor e da grandeza de alma. Nós queremos que Deus lhe dê toda a bênção e que a luz divina ilumine toda a sua vida ( Fonte: Arquivo pessoal da prof. Djanira).

O que se constata ao final é que o arquivo memória de Djanira sugere mais do que uma preocupação sistemática com a preservação do passado escolar, mostra-se como um esforço em dar um sentido a esse material constitutivo do eu, que possui interlocução entre a construção da autoimagem e as cenas do cotidiano profissional. Questões educacionais abrem possibilidades de se revisitar as práticas escolares cotidianas e perceber os saberes privilegiados no projeto educacional que sugere padrões de comportamentos e formas de interpretar o mundo. Neste texto foi desenvolvido o olhar que privilegia a perspectiva da profissional da educação que revela, em sua escrita, a educadora que passou parte de sua vida no ensino público e que viveu momentos 
que mobilizaram a Escola Melo Viana e toda uma comunidade escolar, projetando a escola de ensino de qualidade nas décadas de 70 e 80 do século XX. Além disso, a opção metodológica adotada permitiu o entrecruzamento de documentos com os registros autobiográficos, estratégia que conduziu ao delineamento das fontes para além do tratamento de forma convencional. Esse tipo de escolha pressupõe uma perspectiva de conhecimento que coloca em destaque as práticas de arquivamento e a importância de guardar objetos e escritos de natureza escolar. O estudo levou-nos a projetar nosso olhar sobre o lugar e a importância em se trabalhar com arquivo pessoal de professoras que fazem de seus guardados um legado para se entender a educação.

\section{Referências:}

ARTIÈRES, P. Arquivar a própria vida. Estudos históricos. Rio de Janeiro, n.21, CPDOC/FGV, p.9-34, 1998.

CASTILLO, A.G. Los archivos europeo de la escritura popular. Boletín acala Archivamos, Alcala, n.38, p.5-11, out.2000.

CAVACO, M. H. Ofício de Professor: o tempo e as mudanças In: NÓVOA, A. (org). Profissão professor. Porto: Porto Editora,1995.

CIAVATTA, M. O mundo do trabalho em imagens a fotografia como fonte histórica. RJ: DP\&A, 2002.

ESCOLANO, A. Tiempos y espacios para la escuela, ensayos históricos. Biblioteca nueva. 2000.

FRAIZ, P. A dimensão autobiográfica dos arquivos pessoais: O arquivo de Gustavo Capanema. Estudos Históricos, RJ, n.21, p.59-87, 1998.

FOUCAULT, M. Vigiar e punir. Petrópolis:Vozes, 1986.

GALVÃO, Ana M. O. Ler/Ouvir folhetos de Cordel em Pernambuco (1930-1950). BH, FaE UFMG, 2000.

LEJEUNE, P. O pacto autobiográfico. Senil, coll "Poética", 1975.

MIGNOT, Ana C. V. Escritas invisíveis: diários de professoras e estratégias de preservação da memória escolar In SOUZA, Elizeu C.; MIGNOT, Ana C V. (orgs). Histórias de vida e formação de professores. RJ: Quartet: FAPERJ, 2008. 
- Em busca do tempo vivido: autobiografias de professoras In

MIGNOT, Ana C. V.; SANTOS, M. T. (org). Práticas de memória docente. SP: Cortez, 2003.

OLIVEIRA, I. B. de; SGARBI, P. Estudos do cotidiano \& educação. BH: Autêntica Editora, 2008.

RIBEIRO, Renato Janine. Memórias de si, ou... Estudos históricos. RJ, n.21, CPDOC/FGV, p.35-42, 1998.

PASSEGGI, M. C. \& BARBOSA, Tatyana M. (org). Narrativas de formação e saberes biográficos. Natal, RN:EDUFRN; SP: Paulus, 2008 .

SANTOS, M T. De ontem e de hoje: práticas escolares em diários íntimos de professoras In SOUZA, Elizeu C; MIGNOT, Ana C. V. (orgs). Histórias de vida e formação de professores. RJ: Quartet: FAPERJ, 2008.

VINÃO FRAGO, A história de la educacion e historia cultural: possibilidades, problemas, cuestiones. Revista Brasileira de Educação, n 0, ANPEd, 1995.

Recebido em: 15/12/2014

Revisado em: 11/04/2016

Aprovado para publicação em: 20/04/2016

Publicado em: 30/04/2016 